\title{
EDITORIAL
}

\section{HERMES: good reasons for harmonising education and training in respiratory medicine}

\author{
R. Loddenkemper*, T. Séverin" ${ }^{\#}$ J-L. Eiselé" ${ }^{\#}$ and P.L. Haslam
}

H ERMES (Harmonised Education in Respiratory Medicine for European Specialists) was launched in 2005 by the European Respiratory Society (ERS), with the aim of harmonising education and training in respiratory medicine. The first deliverable component, a core syllabus representing the content of required knowledge in our specialty [1], will be released at the 2006 ERS Annual Congress in Munich. It is hoped that this document will be used at the national level for the development of training programmes for both trainees and young respiratory specialists, as a first step towards harmonisation in Europe.

Medicine was one of the first professions regulated at the European Union (EU) level. Rules for mutual recognition of diplomas were first set in 1975 in directive 75/362/EEC. This directive concerned the mutual recognition of diplomas, certificates and other evidence of formal qualifications in medicine. Since then, it has been amended several times and lately replaced by a new directive $2005 / 36 / \mathrm{EC}$, which sets the rules for a whole range of regulated professions. This directive guarantees automatic recognition of diplomas and certificates in all EU countries, thus granting free access to the European job market to all European specialists in respiratory medicine.

Regarding respiratory medicine, in 1994, a working group of the European Union of Medical Specialists (UEMS) Pneumology section issued a document that was the basis for the UEMS charter on training [2, 3]. It recommended the following structure for training as a specialist in the field: 6 yrs in medical school, $1 \mathrm{yr}$ of practical training in hospital (socalled "internship"), and 3 yrs of "truncus communis" in internal medicine, followed by a minimum of $3 \mathrm{yrs}$ in pneumology. Since then, however, this document has neither been regularly updated nor properly disseminated. So what is the situation in the real world over a decade later?

A survey undertaken by the ERS, in the autumn of 2005, among the 29 countries that had expressed an interest in participating in the HERMES project showed considerable variation. Both duration and structure of post-graduate specialty training differ strongly, with some countries starting with a common trunk and others starting directly with specialisation in respiratory medicine. Also, postgraduate

*Lungenklinik Heckeshorn, Berlin, Germany. "European Respiratory Society, Lausanne, Switzerland. "Imperial College and Royal Brompton Hospital, London, UK.

CORRESPONDENCE: R. Loddenkemper, Lungenklinik Heckeshorn, Zum Heckeshorn 33, D-14109 Berlin, Germany. Fax: 49 3080022286. E-mail: loddheck@zedat.fu-berlin.de training duration varies from 4 to 7.5 yrs. Furthermore, time spent on different sub-specialty modules (intensive care medicine, thoracic surgery, allergology, oncology, etc.) differs strongly from country to country, thus producing specialists with quite different backgrounds, experiences, strengths and weaknesses, depending on where they have been trained. Based on these findings, one can understand why some young doctors still find it difficult to get a job in another part of Europe despite EU regulations and directives!

A further survey from the ERS also showed that not all countries have a unified syllabus and training programme, that some do not have any exit examinations and that a few countries have no official list of accredited training centres [4].

Based on this analysis, it was felt that a more harmonised pattern of training, including the non-EU countries, would greatly benefit our specialty. Thus, HERMES was launched in 2005 based on the principle that no matter whether trained, for example, in Sweden, Poland, Russia, France, Portugal, Greece or Turkey, all respiratory specialists should possess the same core skills and abilities. Once these standards are set, free movement of respiratory specialists throughout the different phases of their careers would be greatly facilitated. In the long term, such a harmonisation will also raise the general level of qualification of doctors, thus fostering the delivery of similar, high-quality treatments to all patients, wherever they live.

The project has been divided into several phases, each of which have a clearly defined objective. Phase one of the project, which was planned for 2005/2006, was to produce a generally accepted European core syllabus in adult respiratory medicine.

An Educational Task Force was set up, funded by the ERS School. It included 13 international experts representing all the relevant organisations: ERS, ERS School, UEMS, European Board for Accreditation in Pneumology (EBAP), Forum of European Respiratory Societies (FERS), and Permanent Working Group of European Junior Doctors (PWG).

The syllabus has been produced by the Task Force through a three-round Delphi consensus process [5], which was run in close collaboration with a cohort of 50 experts. The cohort comprised 13 experts from the Task Force, 13 experts from the ERS School and 24 national respondents, altogether representing the 29 countries which had expressed their wish to participate in the project through previous invitation sent to their respective national respiratory societies. The syllabus includes 22 core competences divided into nine sections: 1 ) Structure and function of the respiratory system;2) Knowledge 
of respiratory diseases; 3) Symptoms and signs; 4) Diagnostic procedures including monitoring techniques; 5) Treatment modalities and prevention measures; 6) Core generic abilities; 7) Competence in fields shared with other specialties; 8) Knowledge of associated fields relevant to adult respiratory medicine; and 9) Further relevant areas relevant to respiratory medicine (which have in turn been divided into 51 modules).

This document has been developed so as to show what training in respiratory medicine should strive to achieve, and thus might at times go beyond what is local current practice. The document also aims at retaining some areas of competence, which should undoubtedly remain in the field of respiratory medicine. Our hope is that it will help certain countries to retain and further develop sub-specialty fields, such as oncology.

This document will now be disseminated and serve as a basis for a much more ambitious undertaking. Phase two of the project, which is due to start in autumn 2006, foresees the development of European curriculum recommendations, building on the syllabus. While the syllabus represents the content which should be learnt, the curriculum recommendations will include aims and objectives, teaching methods, assessment and educational strategies of the programme [6].

In addition, the project will include establishing a methodology to accredit training centres in each country; developing comprehensive educational materials, such as E-learning resources, enduring materials, Postgraduate courses and other ERS-endorsed School Courses and seminars; and in addition, introducing a voluntary European examination, as is already available in many other specialties [7]. Based on the EU rule of subsidiarity, such an examination will remain purely voluntary. However, it might be a great incentive for young, or not so young, doctors to show that they meet European standards. A survey undertaken in the spring of 2006, among a cohort of over 100 trainees, showed that $66 \%$ were interested in the possibility of sitting a European exit examination, either as a stand-alone examination or in connection with a national examination.

The success of the HERMES project will depend mostly on the interest of individual countries to use its outcomes as a basis on which to develop or update their national syllabi, curricula and training programmes. The European Respiratory Society understands its mission as setting the best standards possible and providing the best quality materials to allow for a broad improvement of respiratory medicine throughout Europe, or beyond to any country which might express interest.

\section{REFERENCES}

1 Loddenkemper R, Séverin T, Eiselé JL, et al. HERMES: a European core syllabus in respiratory medicine. Breathe 2006; 3: 59-70.

2 Dijkman JH, Martinez Gonzales del Rio J, Loddenkemper R, Prowse K, Siafakas N. Report of the working party of the "UEMS Monospeciality Section on Pneumology" on training requirements and facilities in Europe. Eur Respir J 1994; 7: 1019-1022.

3 Union Européenne des Médecins Spécialistes, European Board of Pneumology. UEMS charter on training of medical specialists in the EU: requirements for the specialty pneumology. 1995.

4 Harmonised Education in Respiratory Medicine for European Specialists (HERMES) National survey. www. fersnet.org/hermes/phase_0_nat.htm. Date last accessed: July 10 2006. Date last updated: July 132006.

5 Murphy MK, Black NA, Lamping DL, et al. Consensus development methods, and their use in clinical guideline development. Health Technol Assess 1998; 2: 1-88.

6 Burton JL, McDonald S. Curriculum or syllabus: which are we reforming? Medical Teacher 2001; 23: 187-191.

7 Harmonised Education in Respiratory Medicine for European Specialists (HERMES) International survey. www.fersnet.org/hermes/phase_0_intl.htm. Date last accessed: July 10 2006. Date last updated: July 132006. 